\title{
Effect of the Age of Root-Stock on the Success of Soft-Wood Grafting in Different Cultivars of Mango
}

\author{
Deependra Yadav, Akhilesh Kumar Pal and Surendra Prasad Singh \\ Department of Horticulture, Institute of Agricultural Sciences, Banaras Hindu University, Varanasi 221005, Uttar Pradesh, India
}

\begin{abstract}
An investigation was conducted to study the influence of the age of root-stock on the success and growth parameters of grafts using the method of soft-wood grafting in Amrapali, Mallika, Dashehari, Chausa, Langra and Bombay Green cultivars of mango. The experiment was conducted at Horticulture Garden, Department of Horticulture, Institute of Agricultural Sciences, Banaras Hindu University, during 2015-2016. The results of the present study indicated that the scion Langra performed the best for the two graft success parameters (GSPs) - the sprouting time and \% graft take success and the two graft growth parameters (GGPs) - the scion-shoot girth and the number of leaves per plant; Chausa for the \% graft survival and Bombay Green for the scion-shoot length. Amrapali was observed to perform the worst for the \% graft take success, the scion-shoot girth and the number of leaves per plant, while Mallika performed the worst for the sprouting time, the \% graft survival and the scion-shoot length. The grafting performed on the root-stock at age six months showed the worst for all the GSPs and GGPs. The grafting done on the root-stock at age two months performed the best for all the GSPs and GGPs, except the scion-shoot girth for which the grafting done on one month old root-stock was found to be the best.
\end{abstract}

Key words: Age dependence of graft success, soft-wood grafting, cultivar dependence of graft success, vegetative propagation of mango.

\section{Introduction}

Mango (Mangifera indica L.), originated in Indo-Burma region, is one of the most important fruit crops of India belonging to the family Anacardiaceae. India is endowed with vast germplasm of mango and there are a larger number of commercial varieties at par excellence in quality than the rest of the world [1]. India has ample scope for export of mango pulp and nectar to Europe, USA, Gulf countries, etc. and hence, the mango orcharding promises a lucrative income to India. Nevertheless, for the successful mango orcharding and growing it is necessary that the varieties to be planted are productive, of good quality and adaptable to the climate.

Earlier the mango was mainly propagated by seeds. The seeding trees never produce the mother plants of the cultivars. The vegetative propagation is the only

Corresponding author: Deependra Yadav, M.Sc., research scholar, research field: horticulture-fruit science. way to preserve the unique characters of a genotype and to maintain genetic architecture of the off-spring [2]. There are two popular methods of vegetative propagation of mango, namely, budding and grafting [3]. The basic difference between budding and grafting is the lengths of their scion-shoots. In budding method, scion has a single bud and smaller size, whereas in grafting method the scion has more than one vegetative bud, comparatively longer in size. Out of the different budding and grafting methods, the soft-wood grafting using the cleft method was reported to yield maximum graft success when performed during the period July-October [4].

The production of mango true to type by employing approach grafting is cumbersome time taking and causes gradual denudation of the mother plant, requires a large area for maintenance and low production per unit area. During the past five decades, several detached techniques of grafting have been used successfully as efficient economic and rapid method 
of mango propagation [5-9]. Recently, soft-wood grafting in mango has been investigated by a number of workers in relation to different graft success parameters (GSPs) and graft growth parameters (GGPs) $[10,11]$. Comparative study of grafting methods by Singh et al. [4] concluded that the soft-wood grafting using the wedge technique is the best of all the methods studied. Effect of time on success of softwood grafting in mango was investigated by Karna et al. [12]. Ghritlahare and Ashutosh [13] studied the dependence of soft-wood grafting in sapota on scion procuring and time of grafting. Different graft success and growth parameters in soft-wood grafting in Jamun were investigated by Mulla et al. [14]. Influences of the root-stock age [15, 16] and time of grafting [16] in Aonla were investigated earlier. The present investigation was carried out to study the effect of the age of root-stock on the success and growth parameters of grafts in Amrapali, Mallika, Dashehari, Chausa, Langra and Bombay Green cultivars of mango.

\section{Materials and Methods}

\subsection{Experimental Site}

The present experiment was conducted at the Horticulture Garden, Department of Horticulture, Institute of Agricultural Sciences, Banaras Hindu University, Varanasi, during 2015-2016, to investigate the success of soft-wood grafting in different cultivars of mango (Mangifera indica L.) as influenced by the age of the root-stock.

\subsection{Experimental Design and Treatments}

The experiment was performed with varieties of the mango scion as main plot treatments and ages of the root-stocks as sub-plot treatments. The experiment was conducted in factorial split-plot design with three replications. The main plot treatments were Amrapali, Mallika, Dashehari, Chausa, Langra and Bombay Green and the sub-plot treatments were one month, two months, three months, four months, five months, six months, seven months and eight months.

\subsection{Preparation of Root-Stocks and Scion-Sticks}

Seed stones collected from the local market were sown in the first week of June at $20 \mathrm{~cm}$ within a row and $30 \mathrm{~cm}$ between the rows in the field prepared with well decomposed farm yard manure (FYM) and leaf mould to facilitate easy germination. The grafting was performed on 15th of each month from July 2015 to February 2016. The scion-sticks for the purpose of grafting were selected from the current season, 6-month old terminal-shoots of different mango varieties-Amrapali, Mallika, Dashehari, Chausa, Langra and Bombay Green, from healthy mother trees growing in the Horticulture Garden. The scion-shoots selected were healthy and free from any disease or pest infestation and having healthy buds. The leaves of the bud-sticks were defoliated 7-10 $\mathrm{d}$ before performing the grafting with the help of secateurs leaving their leaf petioles intact. The ages of the root-stocks selected for the grafting were: one month, two months, three months, four months, five months, six months, seven months and eight months.

\subsection{Grafting Work and Care of Grafts}

The soft-wood grafting was performed employing the cleft grafting method. A very sharp grafting knife was used to make a vertical split of 4-8 $\mathrm{cm}$ down the centre of the stub to be grafted. The scion-sticks with 10-15 cm length and 5-15 mm diameter, containing 2-3 buds were selected for the grafting. With the sharp knife the bottom of the bud-stick was cut with two sloping, each in length of $3 \mathrm{~cm}$, on diametrically opposite sides. After proper preparation, the scion was inserted into the cleft of root-stock, taking care that it was held tightly by the pressure of the root-stock itself. The top of the root-stock was wrapped tightly with 200 gauge white polythene strip. As the buds of the shoots were seen in position to sprout these petioles were detached. Scion shoots of each cultivar were grafted on the same day in order to provide the grafts 
uniform environmental conditions for the formation of the union. Standard cultural practices were performed in the nursery.

\subsection{Measurements and Statistical Analysis}

The parameters considered in the present study were, days taken for the bud sprout, success of the grafts, survival of the grafts, linear and radial growths of the scion-shoots and number of leaves per graft. The data were collected for the purpose of determining the \% graft success on 45 days after grafting (DAG); the \% graft survival on 120 DAG and linear and radial growths of the scion-shoots and number of leaves per graft on 180 DAG. The data were subjected to two-way ANOVA test following the method suggested by Panse and Sukhatme [17].
Standard error of means (SE(m)), standard error of deviations (SE(d)) and critical difference (CD) were determined at $5 \%$ level of significance.

\section{Results and Discussion}

\subsection{GSPS}

\subsubsection{Sprout Initiation}

The data presented in Tables 1 and 2 revealed that the age of the root-stock and scion of mango cultivar had significant effect on the time taken for the sprout initiation, whereas the interaction effect of the root-stock age and scion-cultivar did not influence the sprouting time. Out of the six mango cultivars, Langra was found to take the minimum time (13.20 d), while Mallika took the maximum time (14.60 d) of sprouting.

Table 1 Dependence of graft success and growth parameters on the scion of the mango cultivar.

\begin{tabular}{|c|c|c|c|c|c|c|c|}
\hline \multirow[b]{2}{*}{ Treatment } & \multirow[b]{2}{*}{$\begin{array}{l}\text { Cultivar of mango } \\
\text { scion }\end{array}$} & \multicolumn{3}{|c|}{ GSPs } & \multicolumn{3}{|c|}{ GGPs } \\
\hline & & $\begin{array}{l}\text { Number of } \\
\text { days for } \\
\text { sprouting }\end{array}$ & $\begin{array}{l}\% \text { Graft } \\
\text { success }\end{array}$ & $\begin{array}{l}\text { \% Graft } \\
\text { survival }\end{array}$ & $\begin{array}{l}\text { Scion-shoot } \\
\text { length }(\mathrm{cm})\end{array}$ & $\begin{array}{l}\text { Scion-shoot } \\
\text { girth }(\mathrm{mm})\end{array}$ & $\begin{array}{l}\text { Number of } \\
\text { leaves per } \\
\text { plant }\end{array}$ \\
\hline V1 & Amrapali & 14.42 & 48.33 & 76.00 & 18.87 & 13.50 & 21.18 \\
\hline $\mathrm{V} 2$ & Mallika & 14.60 & 57.50 & 73.42 & 18.70 & 13.82 & 21.85 \\
\hline V3 & Dashehari & 13.30 & 63.75 & 76.88 & 20.65 & 15.39 & 23.49 \\
\hline V4 & Chausa & 13.58 & 66.67 & 77.88 & 21.51 & 15.79 & 23.38 \\
\hline V5 & Langra & 13.20 & 69.58 & 75.50 & 21.59 & 15.84 & 24.01 \\
\hline V6 & Bombay Green & 13.74 & 61.25 & 76.58 & 22.54 & 15.70 & 23.31 \\
\hline $\mathrm{CD}$ at $5 \%$ & & 0.84 & 4.86 & N/A & 1.63 & 1.64 & 1.10 \\
\hline $\mathrm{SE}(\mathrm{d})$ & & 0.37 & 2.15 & 1.97 & 0.72 & 0.73 & 0.49 \\
\hline $\mathrm{SE}(\mathrm{m})$ & & 0.26 & 1.52 & 1.39 & 0.51 & 0.51 & 0.35 \\
\hline
\end{tabular}

Table 2 Dependence of graft success and growth parameters on the age of the root-stock.

\begin{tabular}{|c|c|c|c|c|c|c|c|}
\hline \multirow[b]{2}{*}{ Treatment } & \multirow[b]{2}{*}{ Age of root-stock } & \multicolumn{3}{|c|}{ Graft success parameters } & \multicolumn{3}{|c|}{ Graft growth parameters } \\
\hline & & $\begin{array}{l}\text { Number of } \\
\text { days for } \\
\text { sprouting }\end{array}$ & $\begin{array}{l}\% \text { Graft } \\
\text { success }\end{array}$ & $\begin{array}{l}\% \text { Graft } \\
\text { survival }\end{array}$ & $\begin{array}{l}\text { Scion-shoot } \\
\text { length }(\mathrm{cm})\end{array}$ & $\begin{array}{l}\text { Scion-shoot } \\
\text { girth (mm) }\end{array}$ & $\begin{array}{l}\text { Number of } \\
\text { leaves per } \\
\text { plant }\end{array}$ \\
\hline $\mathrm{M}_{1}$ & 1-month & 12.94 & 60.56 & 75.56 & 21.44 & 15.88 & 24.20 \\
\hline $\mathrm{M}_{2}$ & 2-month & 12.83 & 66.11 & 78.11 & 22.23 & 15.68 & 24.37 \\
\hline $\mathrm{M}_{3}$ & 3-month & 13.02 & 65.56 & 77.67 & 21.36 & 15.75 & 24.09 \\
\hline $\mathrm{M}_{4}$ & 4-month & 13.78 & 65.00 & 76.67 & 21.27 & 15.76 & 23.69 \\
\hline $\mathrm{M}_{5}$ & 5-month & 14.28 & 59.44 & 74.28 & 18.70 & 15.56 & 21.80 \\
\hline $\mathrm{M}_{6}$ & 6-month & 14.69 & 53.89 & 72.06 & 18.27 & 13.65 & 20.87 \\
\hline $\mathrm{M}_{7}$ & 7-month & 14.57 & 57.22 & 76.56 & 19.31 & 14.26 & 21.59 \\
\hline $\mathrm{M}_{8}$ & 8-month & 14.33 & 61.18 & 77.44 & 21.23 & 14.50 & 22.33 \\
\hline $\mathrm{CD}$ at $5 \%$ & & 1.16 & 4.95 & $\mathrm{~N} / \mathrm{A}$ & 1.54 & 0.97 & 1.24 \\
\hline $\mathrm{SE}(\mathrm{d})$ & & 0.58 & 2.49 & 3.00 & 0.77 & 0.49 & 0.62 \\
\hline $\mathrm{SE}(\mathrm{m})$ & & 0.41 & 1.76 & 2.12 & 0.55 & 0.35 & 0.44 \\
\hline
\end{tabular}


Likewise, out of the eight root-stock ages, the root-stock of age of two months showed the earliest (12.83 d) sprouting, whereas the root-stock of age of six months took the longest time $(14.69 \mathrm{~d})$ for sprouting. Out of the 48 combinations, Dashehari scion grafted on 2-month old root-stock showed the earliest (11.22 d) sprouting, while Amrapali scion grafted on 7-month old root-stock showed the latest $(16.33 \mathrm{~d})$ sprouting. The present findings are in conformity of the work of Uma Maheswari and Nivetha [18] on soft-wood grafting in Jackfruit (Artocarpus heterophyllus) and Barathkumar [15] on soft-wood grafting in Aonla (Phyllanthus emblica L.).

\subsubsection{Percent Graft Take Success}

The per cent graft take success was found to depend on the age of the root-stock and scion of mango cultivar significantly, whereas the interactions of the root-stock age and scion cultivar were not found to exhibit significant influence on it. The highest (69.58\%) graft take success was noted with Langra, whereas it was the lowest (48.33\%) with Amrapali. With regard to the age of the root-stock, the 2-month old root-stock was found to perform the best (66.11\%), while the 6-month old root-stock showed the minimum (53.89\%) percent graft take success. The lowest (43.33\%) percent graft take success corresponded to the variety Amrapali and root-stock ages 5-7 months, while the highest (76.67\%) percent graft take success corresponded to the combinations of Dashehari/Chausa with root-stock age of two months, and Langra with root-stock ages of 4-5 months. The present results are supported by a study on soft-wood grafting in Aonla, wherein it was concluded that the maximum grafting success was recorded in grafting with 8-month old rootstock [16], in a similar work on Aonla by Barathkumar [15] and a soft-wood grafting study on jackfruit by Uma Maheswari and Nivetha [18]. Further, an investigation of time dependence of the graft success in Jamun (Syzygium cumini (L.) Skeels) employing softwood grafting revealed that the graft success under open condition was the highest in the months November and May, whereas, under controlled condition the maximum graft take was during the months October-December [14]. The time is indirectly related to the age of the root-stock intimately and therefore, the time dependence is implicitly the age dependence

\subsubsection{Percent Graft Survival}

The per cent graft survival did not seem to depend significantly either on the root-stock age or the scion cultivar or their interactions. The scion cultivar Chausa showed the highest (77.88\%) and Mallika the lowest (73.42\%) values for per cent graft survival. The root-stock of age of two months had the highest (78.11\%) graft survival and that of age six months showed the lowest $(72.06 \%)$ value for graft survival. The overall maximum (81.67\%) graft survival corresponded to the combinations of Chausa scion with the root-stock of 1-month age and Langra scion with 3-month old root-stock. The minimum (62.33\%) graft survival was recorded with combination of Mallika scion with 6-month old root-stock. The studies by Uma Maheswari and Nivetha [18] on jackfruit and Barathkumar [15] on Aonla also found age dependence of the \% graft survival.

\subsection{GGPs}

\subsubsection{Scion-Shoot Length}

The length of the scion-shoot depended on the age of the root-stock and scion cultivar significantly. However, the interaction effect of the age of the root-stock and scion cultivar was not found encouraging to influence the scion-shoot length. The cultivar Mallika showed the smallest $(18.70 \mathrm{~cm})$, while the Bombay Green exhibited the maximum $(22.54 \mathrm{~cm})$ scion-shoot growth. The grafting performed on the root-stock of 2-month age recorded the highest $(22.23 \mathrm{~cm})$ length of the scion-shoot and the grafting performed on the root-stock of 6-month age showed the lowest $(18.27 \mathrm{~cm})$ length of the scion-shoot. The least $(15.91 \mathrm{~cm})$ scion-shoot length was found with the combination of Mallika with 
root-stock of 6-month age, while the highest (23.66 $\mathrm{cm})$ scion-shoot length was noted in Bombay Green with root-stock of 2-month age. The younger root-stocks were found to record higher scion-shoot length. The study by Roshan et al. [16] and Barathkumar [15] on soft-wood grafting in Aonla also concluded that the maximum shoot-height was obtained for grafting performed on root-stock of some particular age and grafted on some specific time. Similar findings were also reported by Uma Maheswari and Nivetha [18] for soft-wood grafting in jackfruit.

\subsubsection{Scion-Shoot Girth}

The scion-shoot girth also exhibited significant dependence on the age of the root-stock and the cultivar of the mango scion. However, the interaction effect of the age of the root-stock and cultivar of the mango scion was found to influence the scion-shoot length non-significantly. The minimum $(13.50 \mathrm{~mm})$ scion-shoot girth was recorded for scion cultivar Amrapali, while cultivar Langra showed the maximum $(15.84 \mathrm{~mm})$ scion-shoot girth. The grafting performed on the root-stocks with ages from one month to five months exhibited higher scion-shoot girth as compared to that with ages 6-8 months. The overall minimum $(12.34 \mathrm{~mm})$ scion-shoot girth was found with scion cultivar Amrapali grafted on the root-stock with age of six months, while the maximum (16.99 mm) scion-shoot girth was observed for scion cultivar Chausa grafted on the root-stock with age of one month. The results of the present study find support from the work of Uma Maheswari and Nivetha [18] on soft-wood grafting in jackfruit.

\subsubsection{Number of Leaves per Grafted Plant}

The number of leaves per grafted plant was found to be influenced by the age of the root-stock and scion cultivar, however, the interaction of these two did not appear to influence the number of leaves per graft. The lowest (21.18) number of leaves per plant was observed with Amrapali scion, while scion cultivar Langra yielded the highest (24.01) number of leaves per plant. The minimum (20.87) and maximum (24.37) number of leaves were found with the grafting performed on the root-stocks with two months and six months ages, respectively. The global minimum (17.78) number of leaves per graft was discerned when Amrapali was grafted on 6-month old root-stock, whereas it was the maximum (26.22) in Langra grafted on 1-month old root-stock. The study on soft-wood grafting in Aonla concluded that the maximum number of leaves per shoot was recorded from grafting performed on 8-month old rootstock grafted in the 1st week of December [16] and thus, supports our findings. Similar studies by Uma Maheswari and Nivetha [18] on jackfruit and Barathkumar [15] on Aonla also are found in conformity with the present results.

The present findings on GSPs and GGPs are corroborated by the results of investigation on soft-wood grating in different mango cultivars by Prajapati et al. [10]. These authors reported that the time of sprout initiation was observed to be the minimum in Dashehari and maximum in Rajapuri and the percent graft take success was the maximum in Kesar and minimum in Local-4. The present varietal dependence of the sprouting time and percent graft take success is also supported by the work of Uma Maheshwari and Nivetha [18] on standardization of the age of the root-stock on success of soft-wood grafting in jackfruit. The work of Kaur [19] on different mango scion varieties grafted on the local desi rootstock of mango with wedge grafting also revealed that the graft survival depended significantly on the mango cultivars. Damtew and Assefa [20] found that the root-stock age and grafting season had significant influence on the success of cleft grafting and growth of grafted mango plants. The experiment conducted by Ghritlahare and Ashutosh [13] on soft-wood grafting in sapota also discerned that the grafts performed on July 20th using $10 \mathrm{~d}$ pre-cured scions yielded the maximum growth of scion, incremental length of rootstock, incremental diameter 
of scion, number of leaves per graft, area of largest leaf. Therefore, their study corroborated the results of the present investigation.

The investigation on soft-wood grafting in mango by Karna et al. [12] also support the findings of the present study, wherein these authors concluded that the best performance in parameters, like, \% success, \% survival, scion shoot-length, plant height, number of leaves, scion girth and rootstock girth, was observed in grafting on September 15th.

\section{Conclusions}

Averaged over the ages of the root-stocks, the scion cultivar Langra performed the best for the two GSPs-the sprouting time and \% graft take success and the two GGPs - the scion-shoot girth and the number of leaves per plant. The scion cultivar Chausa performed the best for the \% graft survival and Bombay Green performed the best for the scion-shoot length. Amrapali was observed to perform the worst for the \% graft take success, the scion-shoot girth and the number of leaves per plant, while Mallika performed the worst for the sprouting time, the \% graft survival and the scion-shoot length.

Averaged over the mango scion cultivars, the grafting performed on the root-stock of age six months performed the worst for all the GSPs and GGPs. The grafting performed on the root-stock of age two months performed the best for all the GSPs and GGPs, except the scion-shoot girth for which the grafting done on one month old root-stock was found to perform the best.

\section{Acknowledgment}

One (Deependra Yadav) of the authors is thankful to the Banaras Hindu University for the financial support in the form of BHU-UGC fellowship.

\section{References}

[1] Mandal, B. K. 2010. "Impact of Foliar Spray of Urea and Thio-Urea and Growth Regulator on Bearing and Physio-Chemical Properties of Mango cv. Amrapali.”
Ph.D. thesis, Birsa Agricultural University.

[2] Hartmann, H. T., Kester, D. E., Davies, F. T., and Geneve, R. I. 1997. Plant Propagation Principles and Practices, 6th ed. Massachussets: Hall Eaglewood Cliffs.

[3] Yadav, D., Pal, A. K., and Singh, S. P. 2018. "Vegetative Methods of Plant Propagation: II-Grafting Cutting Layering and Budding in Mango.” International Journal of Pure and Applied Bioscience 6 (3): 575-86.

[4] Singh, K. K., Chauhan, J. S., and Rawat, J. M. S. 2018. "A Review: Vegetative Propagation of Mango (Mangifera indica L.) through Grafting.” JOJ Hortic Arboric 2 (2): 555583.

[5] Islam, M. N., Rahim, M. A., and Farooque, A. M. 2004. "Standardization of Time and Grafting Techniques in Mango under Bangaladesh Condition.” Asian J. Plant Sci. 3 (3): 378-86.

[6] Pereira, M. C. T., Viana, R. C., Correa, H. C. T., and Nietsche, S. 2004. "Evaluation of Grafting Methods in Mango Trees.” Acta Hort. 645: 679-83.

[7] Kumar, S., Ram, S., and Singh, C. P. 2006. "Growth of Dashehari Mango after Grafting on Different Heights of Seedling Root-Stock.” Indian J. Hort. 63: 327-9.

[8] Sampath, P. M., Nagesh, N., Swamy, G. S. K., Nithin Kumar, C. J., Manjunatha Gowda, D. C., and Chongtham, A. D. 2017. "Effect of Grafting Methods on Graft Success and Graft Survival of Kari Ishada Selections.” Int. J. Pure App. Biosci. 5 (5): 944-50.

[9] Ullah, S. S., Malik, S., Kumar, R., and Kumar, M. 2017. "Effect of Time and Technique of Grafting for Quality Production of Nursery Plants of Dashehari Mango (Mangifera indica L.).” Int. J. Curr. Microbiol. App. Sci. 6 (10): 685-90.

[10] Prajapati, G. K. , Patel, M. M., Bhadauria, H. S., Varma, L. R., Modi, D. J. and Garasiya, V. R., 2014. "Study of Softwood Grafting on Different Mango Varieties." The Asian J. Hort. 9 (1): 240-2.

[11] Karna, A. K., Varu, D. K., Panda, P. A., and Hota, D. 2017. "Standardization of Grafting Time and Height on Success of Softwood Grafting in Mango (Mangifera indica L.).” J. Pharmacogn. Phytochem. 6 (5): 2803-7.

[12] Karna, A. K., Varu, D. K., Patel, M. K., and Panda, P. A. 2018. "Effect of Grafting Time on Success of Softwood Grafting in Mango (Mangifera indica L.).” Int. J. Curr. Microbiol. App. Sci 7 (8): 3072-7.

[13] Ghritlahare, S., and Ashutosh. 2018. "Performance of Sapota (Manilkara achras Mill.) Softwood Grafts on Precuring and Different Season.” International Journal of Chemical Studies 6 (6): 1768-72.

[14] Mulla, B. R., Angadi, S. G., Mathad, J. C., Patil, V. S., and Mummigatti, U. V. 2011. "Studies on Softwood Grafting in Jamun (Syzygium cumini Skeels).” Karnataka 
in Different Cultivars of Mango

J. Agric. Sci. 24 (3): 366-8.

[15] Barathkumar, T. R. 2017. "Studies on Effect of Different Age of Rootstocks on Softwood Grafting in Aonla (Phyllanthus Emblica L.).” Journal of Pharmacognosy and Phytochemistry SP1: 1175-7.

[16] Roshan, R. K., Pebam, N., and Panhabhai, D. M. 2013. "Effect of Rootstock Age and Time of Softwood Grafting on Grafting Success in Aonla (Embelica officinalis).” Acta Hortic. 975: 347-50.

[17] Panse, V. G., and Sukhatme, P. V. 1985. Statistical Methods for Agricultural Workers. New Delhi, India: ICAR Publication, 327-40.
[18] Uma Maheshwari, T., and Nivetha, K. 2015. "Effect of Age of the Root-Stock on the Success Soft-Wood Grafting in Jack (Artocarpus heterophyllus Lam.).” Plant Arch. 15 (2): 823-5.

[19] Kaur, S. 2017. "Performance of Grafts of Different Scion Varieties on Local Desi Rootstock of Mango (Mangifera indica L.) under Nursery Conditions.” Chem. Sci. Rev. Lett. 6 (21): 88-93.

[20] Damtew, M., and Assefa, W. 2018. "Influence of Grafting Season and Rootstock Age on the Success and Growth of Mango (Mangifera indica L.) cv. Apple Using Cleft Grafting.” Int. J. Novel Res. Life Sc. 5 (3): 12-8. 